\title{
KARAKTERISTIK PERTUMBUHAN POPULASI ROTIFER (Brachionus rotundiformis) TANPA PEMBERIAN AERASI DAN MIKROALGA SEBAGAI PAKAN PADA MEDIA KADAR GARAM BERBEDA
}

\author{
(Population Growth Characteristic of Rotifer (Brachionus rotundiformis) with No \\ Aeration and Microalgae Augment as Feed on Different Media Salt Level)
}

\section{Fransiskus I.K. Fembri ${ }^{{ }^{*}}$, Erly Kaligis ${ }^{1}$, Inneke F.M. Rumengan ${ }^{1}$}

1. Program Studi Ilmu Kelautan, Fakultas Perikanan dan IImu Kelautan, Universitas Sam Ratulangi, Manado.

*e-mail : fransiskusik@yahoo.co.id

Rotifers are very popular as biocapsul to the larvae of marine fauna, for being the transferor nutrients, mikromolekul, amino acids and unsaturated fatty acids high level, minerals, vitamins and antibiotics from the environment to the larvae without the effects of pollutants. The research method is conducted a rotifer culture experiments in laboratory conditions using media of different salt levels $(20,25,30$ and $35 \mathrm{ppt})$. This study aims to determine the growth rate and the proportion of female rotifer populations that carry the eggs in each treatment. Results of this research showed the highest population growth rate at $20 \mathrm{ppt}$ salinity resulted in an increase in the population growth highest on day 3 is 0.66 , while the other salt levels of $25 \mathrm{ppt}, 30 \mathrm{ppt}$ and $35 \mathrm{ppt} r$ value obtained was $0.45 ; 0.26 ; 0.22$. Based on the proportion of females carrying eggs achieved the highest results in the treatment of 20 ppt salinity is $56.7 \%$ on the first day, however the next day got reduction. In the treatment of 20 ppt salinity decrease occurred due to high population growth was not accompanied by a number of individuals who carried the eggs, so that growth salinity 35 ppt higher start on day 2 to day 5 .

Keywords : Brachionus rotundiformis, population growth, eggs, salinity

Rotifer sangat populer sebagai biokapsul bagi larva fauna laut, karena menjadi pentransfer nutrien, mikromolekul, asam amino dan asam lemak tak jenuh tingkat tinggi, mineral, vitamin dan antibiotik dari lingkungan hidup ke larva tanpa efek polutan. Metode penelitian yang dilakukan adalah percobaan kultur rotifer dalam kondisi laboratorium dengan menggunakan media kadar garam berbeda (20, 25, 30 dan 35 ppt). Penelitian ini bertujuan untuk mengetahui laju pertumbuhan populasi dan proporsi betina rotifer yang membawa telur pada setiap perlakuan. Hasil penelitian menunjukan laju pertumbuhan populasi tertinggi pada kadar garam 20 ppt menghasilkan peningkatan pertumbuhan populasi tertinggi pada hari ke-3 yaitu 0,66 sedangkan pada kadar garam lainnya yaitu $25 \mathrm{ppt}, 30 \mathrm{ppt}$, dan $35 \mathrm{ppt}$ nilai $r$ yang diperoleh adalah 0,$45 ; 0,26 ; 0,22$. Berdasarkan proporsi betina yang membawa telur hasil tertinggi dicapai pada perlakuan kadar garam 20 ppt yaitu $56.7 \%$ pada hari pertama, kemudian pada hari selanjutnya terjadi penurunan. Pada perlakuan kadar garam 20 ppt penurunan terjadi karena pertumbuhan populasi yang tinggi tidak disertai dengan jumlah individu yang membawa telur, sehingga pertumbuhan pada kadar garam 35 ppt lebih tinggi mulai pada hari ke-2 hingga hari ke-5.

Kata kunci : Brachionus rotundiformis, laju pertumbuhan, telur, salinitas. 


\section{PENDAHULUAN}

Rotifer merupakan salah satu zooplankton yang memiliki prospek yang cerah dalam bidang bioteknologi. Hal ini perlu diimplementasikan secara nyata antara lain dengan jalan eksplorasi dan eksploitasi potensi biologi rotifer. Keberadaan rotifer sangat menarik perhatian karena manfaatnya yang besar dalam perairan payau maupun laut bahkan dalam kehidupan manusia.

Rotifer berperan penting di perairan sebagai produsen dalam rantai makanan. Zooplankton ini sangat populer sebagai biokapsul bagi larva fauna laut, karena menjadi pentransfer nutrien, mikromolekul, asam amino dan asam lemak tak jenuh tingkat tinggi, mineral, vitamin dan antibiotik dari lingkungan hidup ke larva tanpa efek polutan (Rumengan, 1997). Rotifer juga merupakan produsen senyawa kimia yang potensial untuk dikembangkan sebagai bahan sediaan farmasitika (Klusemann, et al. 1990), seperti senyawa bioaktif (Rumengan, et al, 2003), kitin (Rumengan, 2010) dan sebagainya.

Sejumlah penelitian mengenai rotifer di Sulawesi Utara telah dilakukan, baik keberadaanya di alam maupun dalam kondisi laboratorium. Seperti viabilitas pada salinitas berbeda (Tjoanda, 1996), dormanisasi pada suhu dan salinitas berbeda (Warouw, 1997), hingga penelitian terakhir yaitu pemanfaatan ikan mentah dalam kultur rotifer (Budianto, 2010; Dali, 2011; Dewanto, 2012) serta pengukuran viabilitas rotifer strain Tumpaan (As'yari, et al. 2014).

Selama ini yang disebutkan salinitas adalah jumlah dari seluruh garam-garam dalam gram pada setiap air laut (Supangat dan Susana, 2003), Laporan tentang pengaruh kadar garam dalam hal ini berupa sejumlah berat garam dapur beryodium yang dilarutkan ke dalam sejumlah volume tertentu dalam air tawar terhadap pertumbuhan rotifer belum banyak diketahui. Tujuan dari penelitian ini adalah untuk mengetahui laju pertumbuhan populasi rotifer pada kadar garam berbeda (20, 25, 30, 35 ppt), serta mengetahui proporsi betina rotifer yang membawa telur pada media kadar garam berbeda.

\section{METODE PENELITIAN}

\section{Tempat dan Waktu Penelitian}

Penelitian ini dilaksanakan di Laboratorium Biologi Molekuler dan Farmasitika Laut, Fakultas Perikanan dan IImu Kelautan dengan waktu penelitian 30 hari.

\section{Bahan Penelitian}

Bahan yang digunakan dalam penelitian ini adalah rotifer jenis $B$. rotundiformis yang diambil dari tambak Desa Tumpaan yang kemudian di kultur dalam bak-bak yang terletak di belakang Fakultas Perikanan dan IImu Kelautan. Bahan lainnya yaitu ikan mentah jenis deho (Euthynus sp.) yang digunakan sebagai pengganti mikroalga sebagai pakan bagi rotifer.

\section{Persiapan Media dan Pakan}

Pada proses awal penelitian dilakukan persiapan media dengan menggunakan wadah berupa toples bervolume 5 liter. air sumur yang tidak mengandung kaporit dimasukkan ke dalam wadah dan dicampur dengan garam dapur beryodium sehingga mencapai kadar garam yang diinginkan yaitu 20, 25, 30, dan 35 ppt.

Pakan rotifer yang digunakan dalam penelitian ini adalah hasil dari penguraian ikan mentah jenis deho dengan bantuan bakteri, ikan sebanyak 3 gram dimasukkan ke dalam wadah kultur. Media dibiarkan selama 2-3 hari agar ikan yang dimasukkan dapat seutuhnya terurai dengan bantuan bakteri.

\section{Pelaksanaan Eksperimen}

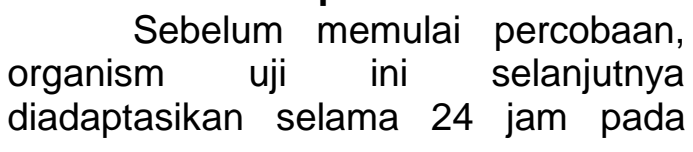


beberapa media kadar garam berbeda yaitu 20, 25, 30 dan 35 ppt. Wadah yang digunakan dalam proses adaptasi berupa toples berkapasitas 5 liter. Rotifer dikultur di dalam toples yang berisi ikan mentah jenis deho (Euthynus. Sp.) sebagai pengganti pakan mikroalga.

Saat eksperimen, awalnya dilakukan penyaringan media dengan menggunakan plankton net dengan mata jaring $100 \mu \mathrm{m}$ dari wadah adaptasi untuk mendapatkan media murni tanpa rotifer. Kemudian media ini dimasukkan pada wadah bervolume 5 $\mathrm{ml}$ yang dijadikan media penelitian. Hal ini dilakukan untuk mengurangi stres pada rotifer bila dalam penelitian menggunakan media baru. Pada setiap wadah dimasukkan rotifer tanpa telur sebanyak 5 individu. Setiap perlakuan kadar garam menggunakan 21 wadah dengan pengamatan setiap hari yang diambil pada 3 wadah selama 7 hari.

\section{Analisis data}

Data kepadatan rotifer selama pengamatan kemudian dianalisis untuk mendapatkan laju pertumbuhan populasi (Tarumingkeng, 1992) :

$$
r=\frac{\ln N t-\ln N_{0}}{\mathrm{t}}
$$

Keterangan:

$r=$ Laju pertumbuhan jumlah populasi $B$. rotundiformis per hari

$\mathrm{Nt}=$ jumlah populasi B.rotundiformis setelah t hari.

$\mathrm{No}=$ jumlah populasi awal B.rotundiformis.

$\mathrm{t}$ = waktu pengamatan

Selanjutnya data pertumbuhan rotifer yang diperoleh ditransformasi (akar kuadrat). Hasil tranformasi kemudian dianalisis secara statistik menggunakan Rancangan Faktorial (RAL) dengan perlakuan kombinasi kadar garam dan waktu (hari). Total keseluruhan berjumlah 28 perlakuan dengan 3 kali ulangan. Dalam menghitung produktifitas (\%) rotifer yang menghasilkan telur digunakan rumus :

Proporsi $=$ jumlah betina bertelur $\times 100$ jumlah individu

\section{HASIL DAN PEMBAHASAN}

Hasil dari pengamatan yang telah dilakukan berupa data jumlah total individu rotifer $B$. rotundiformis yang dikultur pada media menggunakan ikan mentah dengan perlakuan 4 kadar garam berbeda disajikan pada Tabel 1 .

Pada Tabel 1 ditunjukkan bahwa jumlah total pertambahan individu $B$. rotundiformis tertinggi dihasilkan pada media dengan kadar garam 20 ppt dengan total individu sebanyak 337, diikuti oleh media 25 ppt sebesar 187, kemudian 30 ppt sebesar 111 , dan yang terendah terdapat pada kadar garam 35 ppt sebesar 108 .

Menurut Dahril (1996), ketika kondisi media yang baik dengan kadar garam yang ideal, kemudian tersedia nutrisi yang mencukupi dalam media kultur dapat menyebabkan terjadinya pertambahan populasi $B$. rotundiformis dengan cepat. Selain itu populasi rotifer dapat mengalami penurunan yang cepat bila kondisi kadar garam bertambah karena kondisi ini tidak lagi dapat mendukung pertumbuhan.

Tabel 1. Jumlah total individu B.rotundiformis (ind $/ \mathrm{ml}$ ) pada seluruh pengamatan selama 7 hari.

\begin{tabular}{ccccc}
\hline Waktu & \multicolumn{4}{c}{$\begin{array}{c}\text { Jumlah total rotifer } \\
\text { (individu) }\end{array}$} \\
& \multicolumn{4}{c}{. } \\
& 20 & 25 & 30 & 35 \\
& ppt & ppt & ppt & ppt \\
\cline { 2 - 5 } 1 & 30 & 22 & 18 & 16 \\
2 & 43 & 56 & 23 & 20 \\
3 & 110 & 59 & 33 & 29 \\
4 & 63 & 25 & 12 & 22 \\
5 & 42 & 15 & 13 & 7 \\
6 & 31 & 10 & 7 & 8 \\
7 & 18 & - & 5 & 6 \\
\hline Total & 337 & 187 & 111 & 108 \\
\hline
\end{tabular}




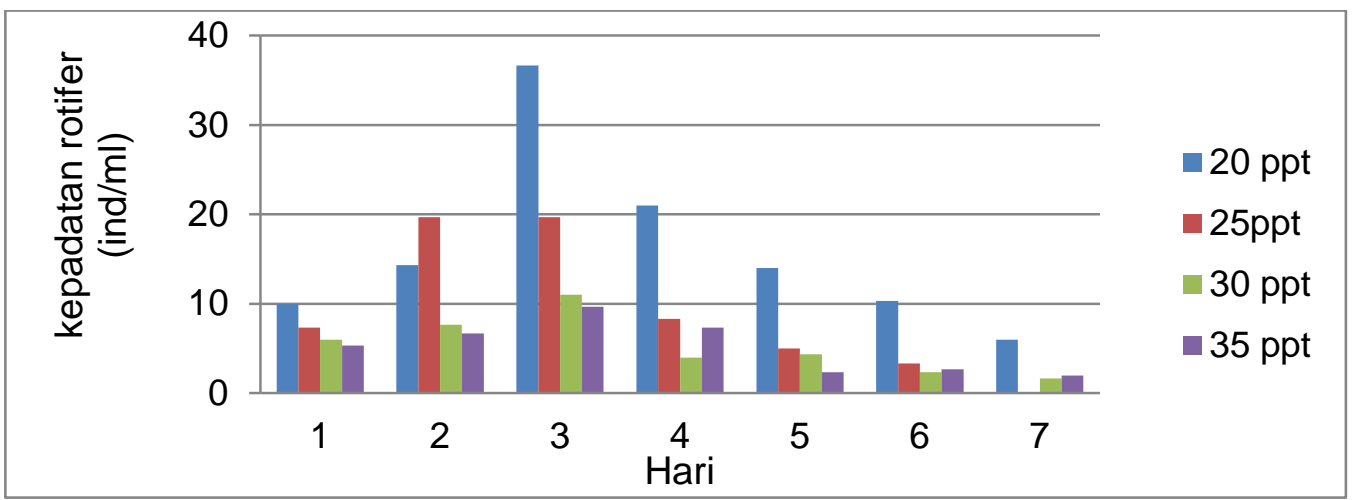

Gambar 1. Rata-rata kepadatan rotifer selama 7 hari pada media kadar garam berbeda

Pola pertumbuhan rotifer selama 7 hari pada masing-masing media disajikan pada Gambar 6. Grafik menunjukkan pola pertumbuhan yang mirip pada seluruh perlakuan. Dalam 7 hari masa kultur, pertumbuhan cenderung tinggi pada hari ke-3 dan mulai menurun hingga hari ke-7. Rotifer yang dikultur pada kadar garam 20 ppt menunjukkan pertumbuhan tertinggi dibanding perlakuan lainnya dengan rata-rata kepadatan 36,67 ind $/ \mathrm{ml}$ pada hari ke-3. Dari hasil penelitian juga diketahui bahwa semakin tinggi kadar garam cenderung mengakibatkan penurunan pertumbuhan rotifer. Perlakuan pada media kadar garam 35 ppt menghasilkan pertumbuhan rotifer paling rendah yaitu mencapai puncak pada hari ke-3 dengan rata-rata 9,67 ind $/ \mathrm{ml}$. Hasil analisis statistik pertumbuhan rotifer di antara seluruh perlakuan menunjukkan bahwa pengaruh interaksi antara kadar garam dan waktu mempengaruhi pertumbuhan rotifer. Artinya ada perbedaan nyata pertumbuhan rotifer di antara perlakuan.

Laju pertumbuhan populasi $(r)$ merupakan parameter umum yang menyediakan pengetahuan tentang kondisi yang cocok pada rotifer (Xi et al. 2005), dan parameter ini digunakan dalam kajian pertumbuhan populasi. Laju pertumbuhan populasi rotifer dalam penelitian ini ternyata dipengaruhi oleh kadar garam pada media.
Pada Gambar 2 menunjukkan penggunaan kadar garam 20 ppt menghasilkan peningkatan pertumbuhan populasi tertinggi pada hari ke-3 yaitu 0,66 sedangkan pada kadar garam lainnya yaitu 25 ppt, 30 ppt, dan 35 ppt nilai $r$ yang diperoleh adalah 0,$45 ; 0,26 ; 0,22$. Hasil ini mengindikasikan adanya potensi rotifer untuk bertumbuh pada media kultur menggunakan ikan mentah.

Hasil tertinggi dicapai pada perlakuan kadar garam 20 ppt yaitu $56.7 \%$ pada hari pertama, kemudian pada hari selanjutnya terjadi penurunan. Pada perlakuan kadar garam 20 ppt penurunan terjadi karena pertumbuhan populasi yang tinggi tidak disertai dengan jumlah individu yang membawa telur, sehingga pertumbuhan pada kadar garam 35 ppt lebih tinggi mulai pada hari ke-2 hingga hari ke-5.

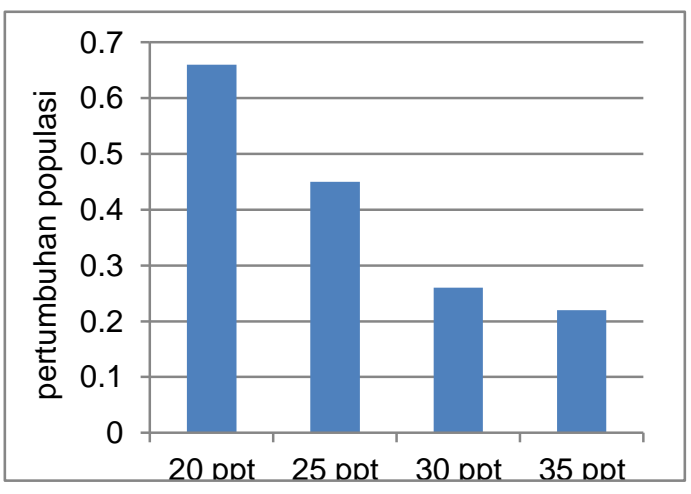

Gambar 2. Laju pertumbuhan populasi (r) rotifer pada kadar garam berbeda. 


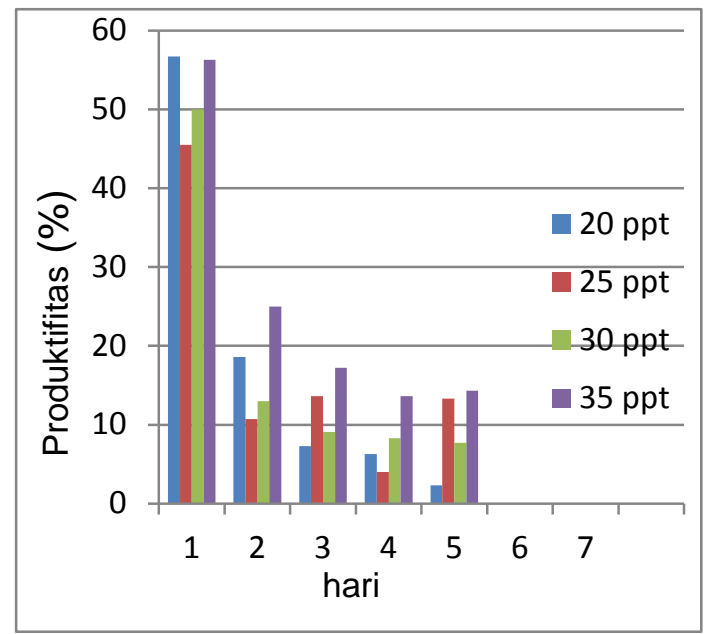

Gambar 3. Produktifitas (\%) telur yang dihasilkan pada kadar garam berbeda.

Hasil ini berhubungan dengan laju pertumbuhan populasi dimana pada perlakuan 20 ppt menunjukkan nilai tertinggi.

Kadar garam merupakan salah satu faktor pembatas dalam kultur rotifer (Hagiwara et al. 1995). Rotifer berkembang dengan baik pada kadar garam 10 sampai 20 ppt dan mampu hidup pada kisaran kadar garam 5-40 ppt dan bersifat eurihalin (Mudjiman, 2004). Penelitian sebelumnya telah mengungkapkan bahwa pemberian ikan mentah sebagai medium pertumbuhan tanpa aerasi serta pengelolaan kualitas air telah berhasil digunakan dalam kultur rotfer (Rumengan, 2010). Dalam kultur selama 2 hari dengan menggunakan bak fiber dengan ukuran panjang 125 $\mathrm{cm}$, lebar $81 \mathrm{~cm}$ dan tinggi $75 \mathrm{~cm}$, kepadatan rotifer dapat mencapai 2000 ind $/ \mathrm{ml}$. Hasil ini melampaui pertumbuhan rotifer dalam sistem sirkulasi dengan pemberian pakan mikroalga, pertumbuhan populasi rotifer hanya mencapai $180 \mathrm{ind} / \mathrm{ml}$ dalam waktu 6 hari (Kurnia, 2006).

\section{KESIMPULAN}

1. Laju pertumbuhan populasi $(r)$ tertinggi pada kadar garam 20 ppt dengan rata-rata 0,66 .

2. Proporsi rotifer betina yang membawa telur dipengaruhi oleh kadar garam berbeda, rotifer yang membawa telur tertinggi terjadi pada hari ke-1 yaitu $56.2 \%$ pada kadar garam 20 ppt.

\section{DAFTAR PUSTAKA}

Asy'ari., Kaligis. E., Wullur, S., Rimper, J., 2014. Viabilitas Rotifer Brachionus rotundiformis Strain Tumpaan pada Kadar garam Berbeda. Jurnal IImu dan Manajemen Perairan (ISSN 2337-4403), 2 (1):20-26.

Budianto, 2010. Eksplorasi telur dorman Rotifer Brachionys rotundiformis asal perairan pesisir poigar bolaang mongondow Sulawesi utara. Tesis. UNSRAT. Manado. 64 hal

\section{Dali, F.A. 2011. Karakteristik Bakteri yang Berasosiasi pada Medium Kultur Massal Rotifer (Brachionus rotundiformis). Tesis, UNSRAT. Manado.}

Dewanto, D. 2012. Kultur Massal Rotifer Brachionus rotundiformis Tanpa Mikroalga dan Aerasi. Tesis. UNSRAT. Manado. 30-32 hal.

Klusemann, J., Kleinov. W., Peters, W. 1990. The hard parts (trophi) of the rotifer mastex do contain eitin : evience from studies on Brachionus Plicatilis. Zooplogisches Institute Der Universitat Zu Kroln, Dfisselodorf, niversity/itsstrase. Weyertal 119, d-5000 Krln 41, Federal Republic of Germany.

Rumengan, I.F.M. 1997. Marine Rotifers (Brachionus spp) as a Brocapsule For Larva of Virious Marine Fana. Wartawipek. No 19 UNSRAT. Manado. 63 hal 
Rumengan, I.F.M., Damongilala, L., Posangi, J., 2003. Isolasi medium kultur dan ekstrasi senyawa bioaktif rotifer (Brachionus rotundiformis) strain local. Laporan Hasil Penelitian, Program Penelitian Dasar di Perguruan Tinggi Tahun Angkatan 2002/2003. Universitas Sam Ratulangi.

Rumengan, I.F.M. 2010. Eksplorasi Kitin dan Khitosan dari Zooplankton Laut Serta Karakteristik Sifat Kimia-Fisika dan Farmasetika Sediaan Farmasi. Laporan Akhir Program Insertif Risert Dasar Kementrian Negara Risert dan Teknologi.

Tjoanda, C. 1966. Lulus Hidup, Fekunditas dan Laju Miksis Rotifer Brachionys rotundiformis yang Dikultur pada Kadar garam yang Berbeda. Skripsi. Fakultas perikanan dan ilmu kelautan UNSRAT

Tarumingkeng, R.C. 1992. Dinamika pertumbuhan Populasi Serangga. Pusat Antar Universitas-IImu Hayati. Institut Pertanian Bogor. 145 hal.

Warouw, V. 1997. Potensi Dormansi Rotifer Brachionys rotundiformis yang Dikultur dalam Kadar garam dan Suhu Berbeda. Tesis, UNSRAT, Manado. 58 hal. 